
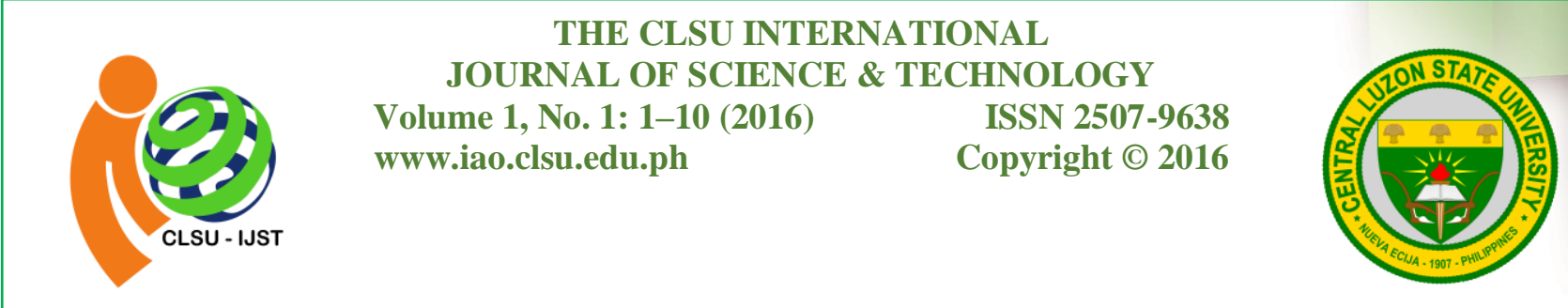

\title{
Formulation of a Sports Drink from Fermented Whey
}

\author{
Mina Abella ${ }^{1}$, Maria Lourdes Leano², Jasmin Malig ${ }^{2}$, Gizelle Martin², \\ Celeste Dela $\mathrm{Cruz}^{3}$, Alma De Leon*2
}

IPhilippine Carabao Center, Central Luzon State University, Science City of Munoz, Nueva Ecija,
Philippines, ${ }^{2}$ Department of Food Science and Technology, College of Home Science and Industry,
Central Luzon State University, Science City of Munoz, Nueva Ecija, Philippines, ${ }^{3}$ Department of
Hospitality Management, College of Home Science and Industry, Central Luzon State University,
Science City of Munoz, Nueva Ecija, Philippines
Email for correspondence: almadeleon444@ @otmail.com

Submitted April 2016, Accepted June 2016, Published August 2016

\begin{abstract}
The formulation of a sports drink made from fermented whey was optimized. Acid whey (3.32\% lactose) was fermented using cultures of Lactobacillus bulgaricus and Streptococcus thermophilus. The resulting fermented whey (2.84\% lactose) was used as the main raw material in the preparation of sports drinks with various levels of stabilizer added $\left(\mathrm{T}_{1}=0 \%, \mathrm{~T}_{2}=0.1 \%, \mathrm{~T}_{3}=\right.$ $0.125 \%$, and $\mathrm{T}_{4}=0.15 \%$ ). Physicochemical analysis, microbial analysis, sensory evaluation, and proximate analysis were conducted to determine the quality, acceptability, and storage life of the sports drinks. Results revealed that the drinks progressively became more viscous with increasing levels of stabilizer. However, the addition of stabilizer did not affect the $\mathrm{pH}$ or Total Soluble Solids (TSS) of the drinks. TSS and pH significantly fluctuated during storage. Within the 30-day storage with the exception of $\mathrm{T}_{1}$, the total aerobic plate count (APC), yeast and mold counts (YMC), and coliform counts of all the treatments were less than $10^{2} \mathrm{cfu} / \mathrm{mL}$, which is microbiologically acceptable. Sensory evaluation showed that $\mathrm{T}_{3}$ was the most liked sample (6.58). All the sports drink types formulated were found to be statistically comparable to a known commercial brand in terms of their mean liking ratings for color, aroma, taste, and mouth-feel. Just about right (JAR) results revealed that the stabilizer-added drinks had too much orange flavor. $\mathrm{T}_{3}$ contained $22.1 \%$ carbohydrates, thus it could be accordingly classified as a 'hypertonic sports drink'.
\end{abstract}

Key words: Acid whey, fermented whey, lactose, sports drink, and stabilizer

\section{INTRODUCTION}

The transformation of otherwise useless by-products in food manufacturing is highly desirable for food processors and companies. In cheese manufacturing, the yellow-green, watery liquid that separates from the curd is called whey (Smithers et al. 1996). The utilization of whey to 
produce whey-based beverages has recently received increasing interest owing to the increasing consumption of lactic acid beverages such as yogurt and milk-like drinks. However, the poor mouth-feel and watery characteristics of such products are drawbacks for their consumption.

A more useful approach to exploit the use of whey other than whey treatment and disposal is to use whey to manufacture high-energy, nutritious, and mineral-rich sports drinks. A desirable sensory profile could be achieved through whey fermentation. Whey contains nearly half of all solids found in whole milk (Chandan et al. 1982). These solids are predominantly lactose but contain proteins, fat, minerals, and vitamins. With the reduction in the lactose content of whey, whey could be processed into a lactic acid beverage. Whey fermentation by lactic acid bacteria (LAB) could decrease the high lactose content of whey, producing mainly lactic acid and other metabolites such as aroma compounds, contributing to the flavor and texture and increasing the carbohydrate solubility and sweetness of the end product (Mauriello et al. 2001). Lactose on hydrolysis gives glucose and galactose, which are instant energy-providing constituents. As such, whey could be a low-cost starting material that could be transformed into a sports drink in order to meet instant energy requirement and compensate for electrolytic loss.

The main objective of the study was to optimize the formulation of a sports drink using fermented whey supplemented with different levels of stabilizer. Physicochemical analysis, microbial analysis, proximate analysis, and sensory evaluation were conducted to determine the quality, acceptability, and storage stability of the sports drink formulated.

\section{MATERIALS AND METHODS}

\section{Materials}

The acid whey (mozzarella cheese by-product) used in the development of sports drink with different levels of stabilizer was obtained from the DVF Dairy Farm in Talavera, Nueva Ecija, Philippines. Freeze-dried cultures of Lactobacillus bulgaricus and Streptococcus thermophilus that were used in the fermentation of the whey were obtained from the Philippine Carabao Center (PCC) at CLSU, Science City of Muñoz, Nueva Ecija, Philippines. Diadem ${ }^{\text {TM }}$ AM1434 was used as stabilizer while Sunquick Concentrated Orange Juice and McCormick were used as flavorants. The sucrose, potassium chloride, monopotassium phosphate, rock salt, and sodium citrate used were all food-grade.

\section{Preparation of fermented whey}

The freeze-dried cultures of Lactobacillus bulgaricus and Streptococcus thermophilus were added to the sterilized whey. The mixture was incubated for $4-6 \mathrm{~h}$ at $42^{\circ} \mathrm{C}$ until its $\mathrm{pH}$ reached 4.5. The propagated starter culture was then added to the cheese whey at a rate of $2 \%$ (whey volume basis). The inoculated whey was again incubated at $42^{\circ} \mathrm{C}$ until its $\mathrm{pH}$ reached 4.5 . The fermented whey was centrifuged and filtered using sanitized muslin cloth.

\section{Lactose content determination}

Samples of unfermented and fermented whey were subjected to lactose content determination using the automatic milk analyzer (Milko Sonic) at the Milka Krem Plant in Muñoz, Nueva Ecija, Philippines.

\section{Preparation of sports drink}

The formulated sports drink contained $82 \%$ fermented whey, $13.36 \%$ flavor, $3.94 \%$ sucrose, $0.5 \%$ artificial flavor, $0.02 \%$ sodium chloride, $0.01 \%$ sodium citrate, $0.007 \% \mathrm{~K}_{2} \mathrm{HPO}_{4}$, and $0.005 \%$ 
KCl. The weighed stabilizer and sugar were mixed together. Then the mixture was stirred into the fermented whey until thoroughly dissolved; the rest of the ingredients were then added. Then the mixture was heated at $90^{\circ} \mathrm{C}$ for $2 \mathrm{~min}$. After heating, it was cooled to $85^{\circ} \mathrm{C}$, transferred to PET bottles rinsed with $0.1 \%$ sodium benzoate, and covered immediately. To sterilize the cap, the hotfilled bottles were inverted for $2 \mathrm{~min}$ before the bottles were cooled to room temperature.

\section{Treatments}

Four levels of stabilizer, namely, $0.0 \%\left(\mathrm{~T}_{1}\right), 0.1 \%\left(\mathrm{~T}_{2}\right), 0.125 \%\left(\mathrm{~T}_{3}\right)$, and $0.15\left(\mathrm{~T}_{4}\right)$ were used as treatments in the study.

\section{Physicochemical analysis}

Viscosity was determined using a Brookfield viscometer on the $7^{\text {th }}$ day. Acidity $(\mathrm{pH})$ and total soluble solids were determined on the $1^{\text {st }}, 3^{\text {rd }}, 7^{\text {th }}, 14^{\text {th }}, 21^{\text {st }}$, and $30^{\text {th }}$ days of storage using a $\mathrm{pH}$ meter and a hand-held digital refractometer, respectively.

\section{Microbial analysis}

The aerobic plate count (APC), yeast and mold count, and coliform count of the sports drinks were determined on the $1^{\text {st }}, 3^{\text {rd }}, 7^{\text {th }} .14^{\text {th }}, 21^{\text {st }}$, and $30^{\text {th }}$ days during the 30 -day storage period.

\section{Sensory evaluation}

On the $21^{\text {st }}$ day of storage the developed sports drinks were evaluated by 50 panelists (athletes) at the College of Home Science and Industry. Each respondent evaluated 5 samples (control, 3 samples with different levels of stabilizer, and a known brand of sport drink) using a blind sequential monadic taste test approach.

Approximately $30 \mathrm{~mL}$ of each sample was served to the assessors one at a time in a balanced arrangement. The samples were coded with 3 alpha-numeric characters to maintain anonymity and avoid bias. The assessors were given water before tasting the samples to cleanse their palates and neutralize their taste buds. In one-on-one interviews, the respondents were asked for feedbacks about the samples

Data collection was done with the help of a structured questionnaire containing both openended and hedonic scale questions. Key Performance Indicators (KPIs) of the test samples included in the questionnaire were overall acceptability (9-point hedonic scale), product ratings (e.g., liking, "just-about right" (JAR) on specific attributes (e.g., color, aroma, taste, and mouth-feel), and purchase intention.

\section{Proximate analysis}

The sports drink with the highest mean acceptability score was submitted to Fast Laboratories for proximate analysis.

\section{Data analysis}

Collected data were analyzed using analysis of variance in split-plot design for $\mathrm{pH}$ and TSS data and factorial design for the sensory data. Means were compared using Least Significant Difference (LSD) at 5\% level of significance.

\section{RESULTS AND DISCUSSION}

\section{Lactose hydrolysis}

Considering that there are many people with lactose intolerance, the researchers thought it was wise to ferment liquid acid whey to reduce its lactose content. Lactobacillus bulgaricus and 
Streptococcus thermophilus were used in the fermentation. Neves et al. (2005) reported that lactic acid bacteria (LAB) ferment whey, a process initiated by lactose hydrolysis. Lactose, through the aid of lactose permease, is transferred into the cell of LAB and hydrolyzed to glucose and galactose, which are then converted to lactic acid.

Using a Milko sonic analyzer, we observed that fermentation reduced the amount of lactose in the whey from $3.32 \%$ (unfermented) to $2.84 \%$ (fermented whey).

\section{Viscosity}

We observed that the drinks progressively became more viscous with increasing level of Diadem $^{\text {TM }}$ AM1434 as stabilizer (see Table 1). Stabilizers modify the mobility of water and thus affect textural properties (e.g., rheology/viscosity, uniformity of appearance, and mouth-feel), as well as the physical functionality and/or physical stability of food and beverages during manufacture, distribution, and consumption.

The thickness of the drinks can also be attributed to the whey proteins aside from the added stabilizer. This was evident in the substantial viscosity of $\mathrm{T}_{1}$ in which no stabilizer was added. According to Huffman (1996), the addition of whey to certain products helps to thicken them, thereby increasing their viscosity, which is important in the production of a wide variety of food including beverages.

Table 1. Viscosities of the sport drinks with different levels of stabilizer

\begin{tabular}{clc}
\hline & Treatments & Viscosity $(\mathrm{mPa} / \mathrm{s})$ \\
$\mathrm{T}_{1}$ & no stabilizer added & 3.0 \\
$\mathrm{~T}_{2}$ & $0.1 \%$ level stabilizer & 8.40 \\
$\mathrm{~T}_{3}$ & $0.125 \%$ level stabilizer & 10.80 \\
$\mathrm{~T}_{4}$ & $0.15 \%$ level stabilizer & 13.80 \\
\hline \hline
\end{tabular}

\section{Acidity (pH)}

The levels of stabilizer did not significantly affect the $\mathrm{pH}$ of the drinks (see Table 2). However, $\mathrm{pH}$ values significantly fluctuated during storage. Acidity progressively increased on the $1^{\text {st }}, 3 \mathrm{rd}, 7^{\text {th }}, 21^{\text {th }}$, and $30^{\text {th }}$ day. However, on the $14^{\text {th }}$ day acidity significantly decreased which may be due to macromolecule degradation, i.e., conversion of whey protein to simpler basic chemical compounds. These basic compounds could have neutralized the acid. Although the $\mathrm{pH}$ fluctuated during the 30 day storage, the values were within an acceptable range for sport drinks, between 2.5 and 4.0 (Samson et al., 2003). 
Table 2. Acidity $(\mathrm{pH})$ of sports drinks as affected by different levels of stabilizer and storage days

\begin{tabular}{cccccc} 
Days of storage & $\mathrm{T}_{1}$ & $\mathrm{~T}_{2}$ & $\mathrm{~T}_{3}$ & $\mathrm{~T}_{4}$ & ${ }^{\mathrm{y}}$ Mean (Days) \\
1 & 3.85 & 3.84 & 3.90 & 3.42 & $3.75^{\mathrm{b}}$ \\
3 & 3.43 & 3.40 & 3.87 & 3.85 & $3.64^{\mathrm{d}}$ \\
7 & 3.92 & 3.42 & 3.47 & 3.42 & $3.56^{\mathrm{e}}$ \\
14 & 3.87 & 3.87 & 3.94 & 3.47 & $3.79^{\mathrm{a}}$ \\
21 & 3.44 & 3.44 & 3.88 & 3.88 & $3.66^{\mathrm{c}}$ \\
30 & 3.93 & 3.40 & 3.47 & 3.41 & $3.55^{\mathrm{f}}$ \\
$\begin{array}{c}\text { xMean } \\
\text { (treatments) }\end{array}$ & $3.74^{\mathrm{A}}$ & $3.56^{\mathrm{A}}$ & $3.76^{\mathrm{A}}$ & $3.58^{\mathrm{A}}$ & $\mathrm{axb}^{\mathrm{ns}}$ \\
\hline \hline
\end{tabular}

${ }^{\mathrm{x}}$ Means followed by different uppercase letters among treatments are significantly different at $\mathrm{p}<.05$.

${ }^{\mathrm{y}}$ Means followed by different lowercase letters among days of storage are significantly different at $\mathrm{p}<.05$.

\section{Total Soluble Solids (TSS)}

Statistical analysis at 5\% level showed that the levels of stabilizer did not affect the TSS mean values of the drinks (see Table 3). During storage, however, TSS values significantly fluctuated. Mean TSS values of drinks significantly decreased on the $1^{\text {st }}, 3^{\text {rd }}$, and 7 th day, but on the $14^{\text {th }}$ day, the TSS of the drinks significantly increased. Significant decrease on the mean TSS was again observed on the $21^{\text {st }}$ day and $30^{\text {th }}$ day.

Table 3. Total soluble solid of sports drinks as affected by the different levels of stabilizer and storage days

\begin{tabular}{cccccc}
\hline \hline Days of storage & $\mathrm{T}_{1}$ & $\mathrm{~T}_{2}$ & $\mathrm{~T}_{3}$ & $\mathrm{~T}_{4}$ & ${ }^{\mathrm{y}}$ Mean ( Days) \\
0 & 21.40 & 20.20 & 20.07 & 19.80 & $20.37^{\mathrm{b}}$ \\
3 & 18.87 & 19.23 & 21.70 & 20.40 & $20.05^{\mathrm{e}}$ \\
7 & 20.53 & 19.63 & 19.33 & 19.43 & $19.73^{\mathrm{f}}$ \\
14 & 21.83 & 20.33 & 19.97 & 20.17 & $20.58^{\mathrm{a}}$ \\
21 & 19.30 & 19.50 & 21.17 & 20.73 & $20.18^{\mathrm{d}}$ \\
30 & 20.53 & 20.50 & 19.93 & 19.80 & $20.19^{\mathrm{c}}$ \\
xMean & $20.41^{\mathrm{A}}$ & $19.90^{\mathrm{A}}$ & $20.36^{\mathrm{A}}$ & $20.06^{\mathrm{A}}$ & $\mathrm{axb}^{\mathrm{ns}}$ \\
\hline \hline
\end{tabular}

${ }^{\mathrm{x}}$ Means followed by different uppercase letters among treatments are significantly different at $\mathrm{p}<.05$.

${ }^{\mathrm{y}}$ Means followed by different lowercase letters among days of storage are significantly different at $\mathrm{p}<.05$.

\section{Microbial analysis}

Fungi such as yeast and mold, which are very resistant to low $\mathrm{pH}$, can grow in formulated sports drinks. As such, four treatments $\left(\mathrm{T}_{1}=0 \%, \mathrm{~T}_{2}=0.1 \%, \mathrm{~T}_{3}=0.125 \%\right.$ and $\left.\mathrm{T}_{4}=0.15 \%\right)$ were subjected to microbial analysis. Shown in Tables 4, 5, and 8 are the total aerobic plate count (APC), yeast and mold count (YMC), and coliform count, respectively, of the sports drinks. 
The Revised Guidelines for the Assessment of Microbiological Quality of Processed Foods (Food and Drugs Administration-Philippines, 2013) pointed out that samples with APC that exceeds $10^{2} \mathrm{cfu} / \mathrm{mL}$ should be rejected as this indicates a potential health hazard or imminent spoilage. The APC of all the treatments with the exception of $\mathrm{T}_{1}$ were less than $10^{2} \mathrm{cfu} / \mathrm{mL}$ (see Table 4). This confirms that samples with stabilizers regardless of level will not be hazardous to health up to the $30^{\text {th }}$ day of storage.

Table 4. Total aerobic plate count (expressed in CFU/ml) of sports drinks

\begin{tabular}{cccccc}
\hline \hline & Day 3 & Day 7 & Day 14 & Day 21 & Day 30 \\
$\mathrm{T}_{1}$ & $<1$ & $<1$ & 2 & 35 & 155 \\
$\mathrm{~T}_{2}$ & 1 & $<1$ & 1 & $<1$ & 61 \\
$\mathrm{~T}_{3}$ & 1 & $<1$ & 1 & $<1$ & 50 \\
$\mathrm{~T}_{4}$ & - & $<1$ & 1 & $<1$ & 62 \\
\hline \hline
\end{tabular}

Foods with low pH values (4.5 and below) usually are not readily spoiled by bacteria but are more susceptible to spoilage by yeast and molds. For product stability and safety, Food and Drugs Administration-Philippines (2013) reported that YMC of sports drinks should not exceed 1 $\mathrm{cfu} / \mathrm{mL}$. Within the 30-day storage of the sports drinks, YMC was $<1 \mathrm{cfu} / \mathrm{mL}$, (see Table 5) revealing that the sports drinks were stable, safe, and acceptable.

Table 5 . Yeast and mold count (expressed in CFU/ml) of sports drinks

\begin{tabular}{cccccc}
\hline \hline & Day 3 & Day 7 & Day 14 & Day 21 & Day 30 \\
\hline $\mathrm{T}_{1}$ & $<1$ & $<1$ & 0 & $<1$ & $<1$ \\
$\mathrm{~T}_{2}$ & $<1$ & $<1$ & 0 & $<1$ & $<1$ \\
$\mathrm{~T}_{3}$ & 1 & $<1$ & - & $<1$ & $<1$ \\
$\mathrm{~T}_{4}$ & $<1$ & $<1$ & - & $<1$ & $<1$ \\
\hline \hline
\end{tabular}

In the entire 30 days storage of the sports drinks, coliform count was $<1 \mathrm{cfu} / \mathrm{mL}$ (see Table 6). This implied that the sports drinks were safe and acceptable. 
Table 6. Coliform count (expressed in CFU/ml) of sports drinks

\begin{tabular}{cccccc}
\hline \hline & Day 3 & Day 7 & Day 14 & Day 21 & Day 30 \\
\hline $\mathrm{T}_{1}$ & $<1$ & $<1$ & $<1$ & $<1$ & $<1$ \\
$\mathrm{~T}_{2}$ & $<1$ & $<1$ & $<1$ & $<1$ & $<1$ \\
$\mathrm{~T}_{3}$ & $<1$ & $<1$ & $<1$ & $<1$ & $<1$ \\
$\mathrm{~T}_{4}$ & $<1$ & $<1$ & $<1$ & $<1$ & $<1$ \\
\hline \hline
\end{tabular}

\section{General acceptability}

A nine-point hedonic scale was used in the evaluation of the general acceptability of the sports drinks with 9 as like extremely and 1 as dislike extremely. High ratings denoted high acceptability of the sample while low ratings signified poor acceptability. The mean overall acceptability ratings of the sports drinks are shown in Table 7.

Table 7. Mean ratings of the general acceptability of the sports drinks as affected by the different levels of stabilizer

\begin{tabular}{|c|c|c|}
\hline \multicolumn{2}{|r|}{ Treatments } & Mean Ratings \\
\hline $\mathrm{T}_{1}$ & no stabilizer added & $6.14^{\mathrm{a}}$ \\
\hline $\mathrm{T}_{2}$ & $0.1 \%$ level stabilizer & $6.00^{\mathrm{ab}}$ \\
\hline $\mathrm{T}_{3}$ & $0.125 \%$ level stabilizer & $6.58^{\mathrm{a}}$ \\
\hline $\mathrm{T}_{4}$ & $0.15 \%$ level stabilizer & $6.36^{\mathrm{a}}$ \\
\hline $\mathrm{T}_{5}$ & known commercial brand of sports drink & $5.84^{\mathrm{b}}$ \\
\hline $\begin{array}{l}\text { Means } \\
\text { Legend } \\
1.00-1 . \\
1.90-2 . \\
2.80-3 . \\
3.70-4 \\
4.60-5\end{array}$ & $\begin{array}{l}\text { lowed by different letters among treatments are sigr } \\
\text { Dislike Extremely } \\
\text { Dislike Very Much } \\
\text { Dislike Moderately } \\
\text { Dislike Slightly } \\
\text { Neutral }\end{array}$ & $\begin{array}{l}\text { erent at } p<.05 . \\
\text { ely } \\
\text { ch } \\
\text { ly }\end{array}$ \\
\hline
\end{tabular}

Mean ratings of the general acceptability of the 5 evaluated samples ranged from 5.84 to 6.58 with a descriptive rating of like slightly to like moderately. The least liked was $\mathrm{T}_{5}$, a known commercial brand of sports drink while $\mathrm{T}_{3}$ that contains $0.125 \%$ stabilizer (6.58) was the most liked. Mean rating of $\mathrm{T}_{3}$ was not significantly different from $\mathrm{T}_{1}$ (no stabilizer added), $\mathrm{T}_{2}(0.1 \%$ level stabilizer), and $\mathrm{T}_{4}(0.15 \%$ level stabilizer) using Duncan's Multiple Range Test as a mean separation technique. This result indicated that these 4 treatments were equally liked.

\section{Hedonic ratings of the different sensory attributes}

Mean liking ratings of the specific sensory attributes of sports drinks are shown in Table 8 . Statistical analysis revealed that the 5 samples of sports drinks were statistically indistinguishable at the 5\% level in terms of their mean liking ratings for color, aroma, taste, and mouth-feel. This result showed that across all these attributes the 5 samples were equally liked. 
Table 8. Mean liking ratings of the specific sensory attributes of sports drinks

\begin{tabular}{clcccc}
\hline \hline & \multicolumn{1}{c}{ Treatments } & Color & Aroma & Taste & Mouth-feel \\
$\mathrm{T}_{1}$ & no stabilizer added & 6.34 & 5.66 & 5.90 & 5.69 \\
$\mathrm{~T}_{2}$ & $0.1 \%$ level stabilizer & 6.36 & 5.72 & 5.76 & 5.74 \\
$\mathrm{~T}_{3}$ & $0.125 \%$ level stabilizer & 6.20 & 5.92 & 6.16 & 5.88 \\
$\mathrm{~T}_{4}$ & $\begin{array}{l}\text { 0.15\% level stabilizer } \\
\mathrm{T}_{5}\end{array}$ & 6.44 & 6.30 & 5.88 & 5.70 \\
& $\begin{array}{l}\text { Known commercial brand } \\
\text { of sports drink }\end{array}$ & 6.12 & 6.06 & 5.64 & 5.80 \\
\hline \hline
\end{tabular}

\section{Just-About-Right ratings of the specific sensory attributes of the sports drinks}

The respondents were asked about their opinions on the attributes of the drinks using the Just-About-Right (JAR) scale which combines intensity and hedonic judgments. Figure 1 shows the percentage of respondents that rated the specific attributes as Too Little, Just-About-Right (JAR), and Too Much. Color was rated from too light, just right, and too dark; aroma, sweetness, and flavor were rated from too weak, just right, and too strong; mouth-feel was rated too watery, just right, and too viscous.
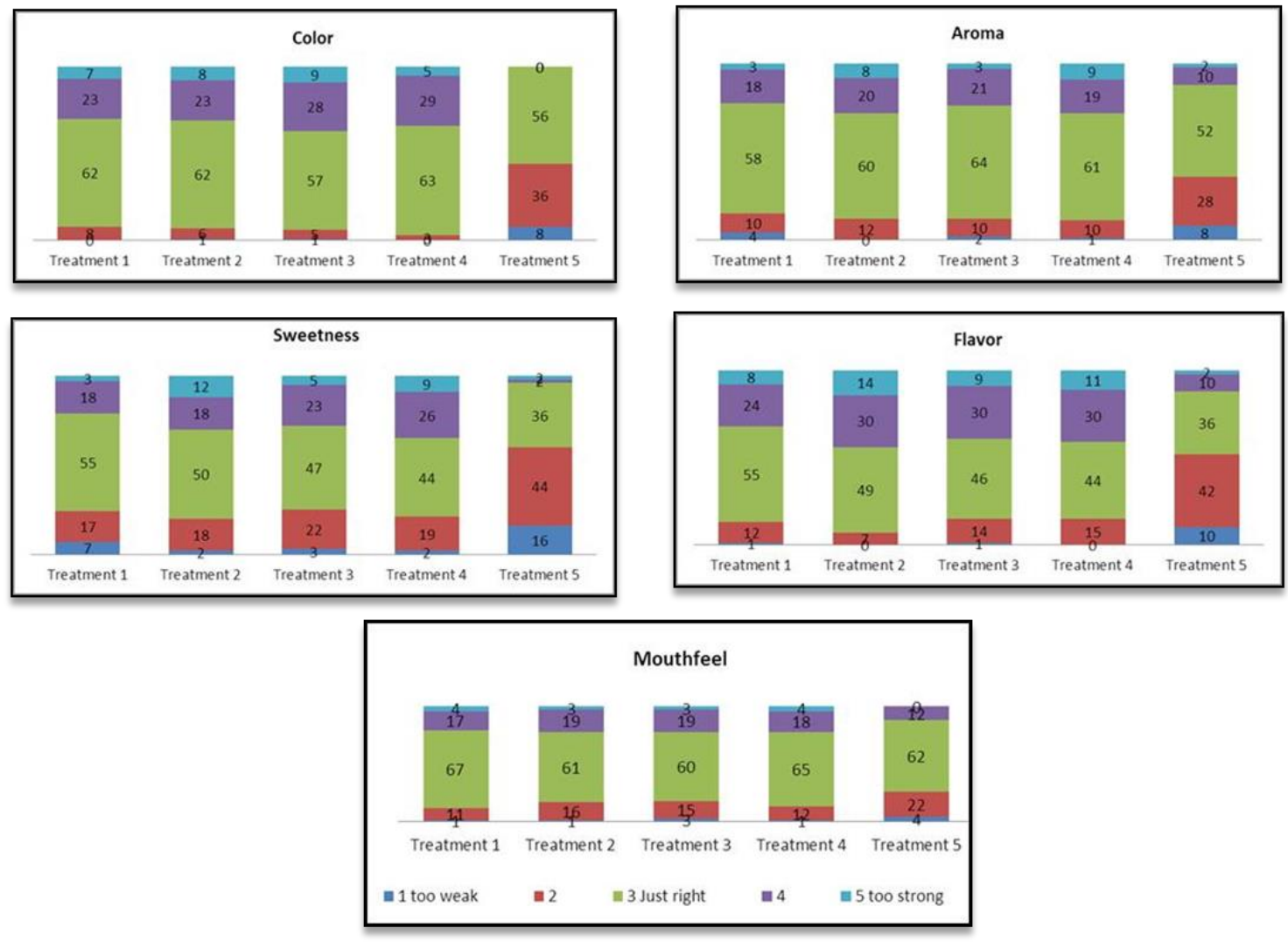

Figure 1. Percentage of the Just About Right (JAR) levels in the sports drinks with different levels of stabilizer

More than $50 \%$ rated the 5 drinks $J A R$ in color, aroma, and mouth-feel intensities. In terms of sweetness, only $\mathrm{T}_{1}$ and $\mathrm{T}_{2}$ were rated $J A R$ by the majority of the respondents. Thirty five percent 
rated $\mathrm{T}_{4}$ a little bit too sweet while $60 \%$ rated $\mathrm{T}_{5}$ lacking in sweetness. The level of flavor differed for those samples with stabilizer $\left(\mathrm{T}_{2}, \mathrm{~T}_{3}\right.$, and $\left.\mathrm{T}_{4}\right)$, and the known commercial brand $\left(\mathrm{T}_{5}\right)$. Less than $50 \%$ of the respondents indicated that these samples were $J A R$ in flavor intensity. Forty four percent, $39 \%$, and $41 \%$ of the respondents rated $\mathrm{T}_{2}, \mathrm{~T}_{3}$, and $\mathrm{T}_{4}$, respectively, to have too strong orange flavor while $52 \%$ rated $\mathrm{T}_{5}$ to have too weak orange flavor.

\section{Proximate analysis}

$\mathrm{T}_{3}$ (as the treatment with the highest general acceptability) was selected for proximate analysis. Its carbohydrates content was found to be $22.1 \%$ (see Table 9) thereby classified as a 'hypertonic sports drink.' Hypertonics contain a high level of carbohydrate (i.e., greater than 8\%) which supplement daily carbohydrate intake normally after exercise to replace muscle glycogen stores. They are suitable for ultra-distance events, such as cycling, marathon, and cross country where high levels of energy are required.

Table 9. Nutritional composition of the sports drink

\begin{tabular}{lc}
\hline \hline Nutritional Composition & Amount (\%) \\
Calories & $92 \mathrm{cal} /$ \\
Protein & $0.60 \%$ \\
Fats & $0.07 \%$ \\
Carbohydrates & $22.10 \%$ \\
Total sugar & $18.10 \%$ \\
Sodium & $0.65 \%$ \\
Potassium & $1.65 \%$ \\
Magnesium & $0.09 \%$ \\
\hline \hline
\end{tabular}

The sports drink contained $0.65 \%$ and $1.65 \%$ of sodium and potassium, respectively. High levels of sodium and potassium constitute what is referred to as a good sports drink. Sodium contributes to palatability and encourages drinking which replaces the water that is lost through sweat.

\section{CONCLUSION}

There are substantial data to support that sports drinks with stabilizer regardless of the level used are safe, stable, and acceptable until the 30th day of storage at room temperature. The most acceptable treatment is the sports drink with $0.125 \%$ level stabilizer $\left(\mathrm{T}_{3}\right)$. Inasmuch as $\mathrm{T}_{3}$ contained $22.1 \%$ carbohydrates, it can be classified as 'hypertonic sports drink.' 


\section{REFERENCES}

Chandan RC, Uebersax MA and Saylock MJ. 1982. Utilization of cheese whey permeate in canned beans and plums. Journal of Food Science. 47:1649-1653.

Food and Drug Administration-Philippines. 2013. Revised Guidelines for the Assessment of Microbiological Quality of Processed Foods. FDA Circular No. 2013-010.

Huffman LM. 1996. Processing whey protein for use as a food ingredient. Food Technology. 50: 49-52.

Mauriello G, Moio L, Moschetti G, Piombino P, Addeo F and Coppola S. 2001. Characterization of lactic acid bacteria strains on the basis of neutral volatile compounds produced in whey. Journal of Applied Microbiology. 90: 928-942.

Smithers GW, Ballard J, Copeland AD, De Silva KJ, Dionysius DA, Francis GL, Goddard C, Grieve PA, McIntosh GH, Mitchell IR, Pearce RJ and Regester GO. 1996. New opportunities from the isolation and utilization of whey proteins. Journal of Dairy Science. 79: 1454-1459. 